\title{
PAEDIATRIC DIAPHYSEAL FEMUR FRACTURE TREATED WITH INTRAMEDULLARY TITANIUM ELASTIC NAIL SYSTEM
}

\author{
Shrawan Kumar Thapa ${ }^{1}$, Krishna Prasad Poudel ${ }^{1}$, Rudra Prasad Marasini ${ }^{1}$, Shankar Dhakal ${ }^{1}$, Robin \\ Shrestha ${ }^{2}$ \\ ${ }^{1}$ Department of Orthopaedics, Bharatpur Hospital, Bharatpur, Nepal \\ ${ }^{2}$ Department of Orthopaedics, College of Medical Sciences, Bharatpur, Nepal
}

Correspondence
Dr. Shrawan Kumar Thapa
Dept. of Orthopaedics,
Bharatpur Hospital, Nepal.
Email:
thapashrawan@gmail.com

DOI: http://dx.doi.org/10.3126/ jemsn.v11i2.13671

\begin{abstract}
Background \& Objectives: Over the few years there has been a marked increase in the use of intramedullary fixation in the management of fracture of shaft of femur in children. The goals should be to stabilize the fracture, to control length and alignment, to promote bone healing and to minimize the morbidity and complications for the child. In this prospective study we intend to evaluate the functional and radiological outcome of diaphyseal fracture of shaft of femur treated with elastic intramedullary nail. Materials \& Methods: All 56 patients with diaphyseal fracture shaft of femur were treated with titanium elastic nail and followed for period of 32 weeks. Results: The In this study, outcome was assessed by using Flynn's criteria of titanium flexible nail outcome score and we found excellent result in 49 cases, satisfactory in six cases and poor in one case. We faced one major complication in form of implant failure and six minor complications inform of superficial wound infection. Conclusion: Elastic intramedullary nail used in treatment of diaphyseal fracture shaft of femur yield excellent functional and radiological outcome. It is easy and simple procedure has low rate of complication. It is physeal-protective, cost effective, does not involve heavy instrumentation and can be performed in small set up. It has minimal risk of infection and no risk of injury to the neurovascular structure.
\end{abstract}

Key words: Flynn's criteria, Pediatric femur fracture, Titanium Elastic Nail System

Citation: Thapa SK, Poudel KP, Marasini RP, Dhakal S, Shrestha R. Paediatric diaphyseal femur fracture treated with intramedullary titanium elastic nail system. JCMS Nepal. 2015;11(2):20-22.

\section{INTRODUCTION}

Femoral shaft fractures are common injuries in pediatric population, and represent roughly $1.6 \%$ of all bony injuries in children. ${ }^{1,2,3}$ Recently, there has been a growing trend towards surgical treatment with widening of the indications to include isolated femoral fractures. Whatever the method of treatment, the goals should be to stabilize the fracture, to control length and alignment, to promote bone healing, and to minimize the morbidity and complications for the child and his/ her family. ${ }^{4}$

Over the few years there has been a marked increase in the use of intramedullary fixation in the management of fracture of shaft of femur in children. To some extent this reflects a more interventionist attitude among pediatric orthopedic surgeons but is also due to technical development notably that of the elastic stable intramedullary nails (ESIN). ${ }^{5}$

Titanium elastic nail (TEN) fixation is an ideal treatment method for femoral fractures, as it represents a compromise between conservative and surgical therapeutic approaches with satisfactory results and minimal complications. ${ }^{6}$

\section{MATERIALS AND METHODS}

In this interventional and prospective study, fifty six patients with diaphyseal fracture femur were treated with titanium elastic nail in Bharatpur Hospital and College of Medical Sciences Teaching Hospital Bharatpur, Chitwan from September 2012 to August 2014. We included displaced closed fracture shaft of the femur and polytrauma, age group range from five to 14 years. We excluded pathological fracture, children below five years of age, fracture shaft of femur with neurovascular deficit.

The surgery was performed under general anesthesia with the patient on the operation table in supine position. Two titanium elastic nails of identical diameter were used. The diameter of the individual nail was selected as per Flynn et al's ${ }^{6}$ 
formula (Diameter of nail= width of the narrowest point of the medullary canal on AP and lateral view $\mathrm{X} 0.4 \mathrm{~mm}$ ) and intraoperative assessment of nail Diameter was chosen so that each nail occupied at least $1 / 3 \mathrm{rd}$ to $40 \%$ of the medullary cavity. Fractures were reduced under fluoroscopic guidance and nails were inserted in retrograde fashion with medial and lateral incision two to three $\mathrm{cm}$ above the physis. Open reduction was required in 11 cases to negotiate the nails to the proximal fragment. The nails were driven proximally so that both were divergent and the tips extended from the level of the distal femoral physis to a point approximately two $\mathrm{cm}$ distal to the capital femoral physis and one $\mathrm{cm}$ distal to the greater trochanteric physis. Quadricep exercise was started from day one, range of movement and mobilization without weight bearing was started as soon as patient became pain free. Partial weight bearing using crutches or walker was started at three weeks and full weight bearing by six to eight weeks depending on the fracture configuration, callus response and associated injuries. All patients were followed up at 4, 8, 12, 24 and 32 weeks for radiological and clinical evaluation. Statistical analysis was done using SPSS version 20 for evaluation. The results were evaluated using Flynn et al's scoring criteria. Nails were removed six to eight months postsurgery when the fracture line was no longer visible radiologically. Ethical clearance was obtained from the ethical clearance committee and written consent was taken from all the patients.

\section{RESULT}

In this study there were 33 boys $(58.9 \%)$ and 23 girls $(41.1 \%)$. Minimum age was six years and maximum age was 14 years while most fractures occurred between nine to 11 years $(44.6 \%)$. The major cause of fracture was road traffic accident in $42(75 \%)$ cases followed by fall from tree in 13 $(23.2 \%)$ cases. Out of 56 fractures, $41(73.2 \%)$ were of the right side and $15(26.8 \%)$ were of left side. Majority of patients (23 or $41.1 \%$ ) had oblique fracture pattern followed by transverse pattern 21 $(37.5 \%)$.

In this study the maximum day of interval between injury and surgery was three days and minimum was one day. Maximum day of hospital stay was 12 days and minimum was five days. Most of the patients stayed in hospital for seven days (28.6\%). In this study partial weight bearing was started from six weeks from post-operative day $(85.7 \%)$ but in some cases due to patient incompliance partial weight bearing was started from 8th week (7.1\%) and in eight patients $(7.1 \%)$ early weight bearing was started with in 5thweek due to good callus formation and clinically painless weight bearing. Full weight bearing was started at 10 weeks $(53.6 \%)$ as well callus formation was seen in Radiology and patient was pain free clinically but in some case full weight bearing was started on 11 th and 12th weeks due to patient incompliance. We found excellent result in 49 cases $(87.5 \%)$, satisfactory in six cases $(10.7 \%)$ and poor in a case $(1.8 \%)$.

We had used $3 \mathrm{~mm}$ nail in 25 cases $(44.6 \%), 3.5 \mathrm{~mm}$ nail in 18 cases $(32.1 \%), 2.5 \mathrm{~mm}$ in 11 cases $(19.6 \%)$ and $4 \mathrm{~mm}$ in 2 cases $(3.6 \%)$.

Twenty four patient out of 56 had limb length shortening of $10 \mathrm{~mm}$ at 24 weeks follow up while four patients had limb length shortening of $12 \mathrm{~mm}$. Thirty five out of 56 patient had angulations of less than five degrees while 19 patients had angulations between five to 10 degree and two patients had angulations of more than 10 degree at 24 week follow up. In this study out of 56 cases 21 cases had full range of movement while 14 had range of movement of 120 degree and 12 cases had range of movement of 110 degree at 24 weeks follow up.

Table 1: Flynn's criteria. TENS outcome score (Flynn et al.) ${ }^{7,8}$

\begin{tabular}{llll}
$\begin{array}{l}\text { Results (Variables } \\
\text { at 24 weeks) }\end{array}$ & Excellent & Satisfactory & Poor \\
$\begin{array}{l}\text { Limb-length } \\
\text { inequality }\end{array}$ & $<1.0 \mathrm{~cm}$ & $<2.0 \mathrm{~cm}$ & $>2.0 \mathrm{~cm}$ \\
\hline Malalignment & 5 degrees & 10 degrees & $>10$ degrees \\
Pain & None & None & Present \\
$\begin{array}{l}\text { Other } \\
\text { complications }\end{array}$ & None & $\begin{array}{l}\text { Minor and } \\
\text { resolved }\end{array}$ & $\begin{array}{l}\text { Major and } \\
\text { lasting }\end{array}$ \\
& & & Morbidity
\end{tabular}

\section{DISCUSSION}

Transverse, short oblique and minimally comminuted fractures are suitable for TEN as mentioned by Flynn et al. ${ }^{9}$ which is consistent to our study where most fractures were either oblique $(41.1 \%)$ or transverse $(37.5 \%)$ involving the middle third of the shaft. Similarly, Ligier et al. reported that among 118 cases, 68 were transverse fracture out of which 16 were comminuted, 28 were spiral out of which nine were comminuted, 22 cases were oblique fracture out of which 10 were comminuted while 47 cases had fracture on proximal third, 35 on middle one third and 36 on distal one third of femoral shaft. ${ }^{10}$ In another series reported by Razak et al. ${ }^{11}$ eleven out of 20 patients had transverse fracture, six had oblique and three had comminuted fracture whereas 14 had fracture on proximal, five on middle and one on distal one third of shaft of femur.

In our study fracture shaft of femur were operated 
within two to four days of injuries which was consistent to a study conducted by El-adl et al. ${ }^{12}$ where fractures were operated within two to four days of injuries.

In our series duration of hospital stay were between five to 12 days where as in a study conducted by Houshian et al. ${ }^{13}$ the mean hospital stays was six days and range of hospital stay was two to 20 days. Only one case out of 56 cases had major complication of implant failure for which implant removal and open reduction and fixation with dynamic compression plating done while six cases had minor complication of superficial wound infection which was healed after regular dressing. In study conducted by Khazzam et al. ${ }^{14}$ there were 14 complications, three re-fractures, two delayed unions, three varus or valgus malalignment, five nail-tip irritations, and one asymptomatic proximal nail migration. In another series reported by El-adl et al. ${ }^{12}$ the following complications were noted: soft tissue and skin problem (9.1\%) in relation to nail ends at the entry points, limb-length discrepancy $(9.1 \%)$, and malunion $(4.5 \%)$.

In our study majority of cases had excellent or satisfactory report which is comparable to series reported by Pulate et al. ${ }^{15}$ results were excellent in 12 patients $(60 \%)$, successful in $7(35 \%)$ and poor in one patient (5\%)and Moroz et al. ${ }^{16}$ was excellent in $150(65 \%)$, satisfactory in $57(25 \%)$, and poor in $23(10 \%)$. This study is not limited to children below five years and above 14 years, communited, high subtrochanteric and pathological fractures.

\section{CONCLUSION}

Elastic intramedullary nail for femoral shaft fracuture in paediatric population is an excellent method of treatment in terms of early stabilization and movement of lower limb. It is ideal and cost effective with short hospital stay and minimal complications. More sample size, long term follow up and multicentric trials are recommended for better results.

\section{REFERENCES}

1. Gardner MJ, Lawrence BD, Griffith MH. Surgical treatment of paediatric femoral shaft fractures. Curr Opin Paediatr. 2004; 16:51-7.

2. Kanellopoulos AD, Yiannakopoulos CK, Soucacos PN. Closed locked intramedullary nailing of paediatric femoral shaft fractures through the tip of the greater trochanter. J Trauma. 2006;60:217-23.

3. Kandil HM. Titanium flexible intramedullary nailing of paediatric femoral shaft fractures. KEAMJ. 2007;13(3):4550 .

4. Metaizeau JP. Stable elastic nailing for fractures of the femur in children. JBJS. 2004;86:954-7.

5. Bary M, Paterson JMH. Flexible intramedullary nails for fractures in children. JBJS. 2004;86-B:947-53.

6. Gamal EA, Mohamed FM, Mohamed AK, Ahmed E. Titanium elastic nail fixation for paediatric femoral and tibial fractures. Acta Orthop. 2009;75:512-20.

7. Flynn JM, Hresko T, Reynolds RA, Blaiser RD, Davidson R, Kasser J. Titanium elastic nails for pediatric femur fractures - a multicenter study of early results with analysis of complications. J Pediatr Orthop. 2001;21(1):4-8.

8. Flynn JM, Luedtke LM, Theodore J, Ganley TJ, Dawson J, Davidson RS, et al. Comparison of titanium elastic nails with traction and a spica cast to treat femoral fractures in children. JBJS. 2004;86:770-7.

9. Flynn JM, Skaggs DL, Sponseller PD, Ganley TJ, Kay RM, Kellie Leitch KK. The operative management of pediatric fractures of the lower extremity. J Bone Joint Surg Am. 2002;84:2288-300.

10. Ligier JN, Metaizeau JP, Prevot J, Lascombes P. Elastic stable intramedullary nailing of femoral shaft fracture in children. JBJS. 1988;70-B:74-7.

11. Razak MYA, El-Karef EA, Soliman AS, Tanagho A. Result of flexible intramedullary nailing in paediatric femoral fractures. Bull Alex Fac Med. 2008;44:729-35.

12. El-adl G, Mostafa MF, Khalil MA, Enan A. Titanium elastic nail fixation for paediatric femoral and tibial fractures. Acta Orthop Belg. 2009;75:512-20.

13. Houshian S, Gothgen CB, Pedersen NW. Femoral shaft fractures in children. Acta Orthop Scand. 2004;75(3):24951.

14. Khazzam M, Tassone C, Liu XC, Lyon R, Freeto B, Schwab J, et al. Use of Flexible Intramedullary Nail Fixation in Treating Femur Fractures in Children. Am J Orthop. 2009;38(3):49-55.

15. Pulate A, Jadhav A, Shah BN. Study of the outcome of titanium elastic nail system in diaphyseal femoral fractures in children. MOA Journal. 2012;7(3):6-8.

16. Moroz LA, Launay F, Kocher MS, Newton PO, Frick SL, Sponseller PD, et al. Titanium elastic nailing of fractures of the femur in children. JBJS. 2006;88(10):1361-6. 